\title{
AVALIACÃO DAS METODOLOGIAS DE INSPECÃO VISUAL DE EDIFICACÕES PARA FINS DE GERENCIAMENTO DE MANUTENÇÕES
}

\author{
GREGÓRIO PACHECO, SILVIA \\ Estudante de Graduação \\ CEFET/MG \\ Minas Gerais; Brasil \\ silvia.gpacheco@hotmail.com
}

\author{
DE PAULO RAMOS, MARCOS \\ Professor EBTT \\ CEFET/MG \\ Minas Gerais; Brasil \\ marcos.ramos@cefetmg.br
}

\author{
MARTINI, RACHEL \\ Professora EBTT \\ CEFET/MG \\ Minas Gerais; Brasil \\ martini@cefetmg.br
}

\author{
GONÇALVES FILHO, EDSON \\ Estudante de Graduação \\ CEFET/MG \\ Minas Gerais; Brasil \\ edson.gonfilho@gmail.com
}

\author{
PENA BORTONE, THIAGO \\ Professor EBTT \\ CEFET/MG \\ Minas Gerais; Brasil \\ thiago.bortone@cefetmg.br
}

\author{
FERREIRA, LUCIANA \\ Professora EBTT \\ CEFET-MG - Curvelo \\ Minas Gerais; Brasil \\ lupiferreira@cefetmg.br
}

\section{RESUMO}

A determinação da vida útil residual e de projeto de uma edificação está intimamente ligada ao planejamento e execução dos processos de manutenção da mesma. A importância dessa manutenção é destacada pela Associação Brasileira de Normas Técnicas - ABNT, em sua norma técnica NBR 6118 (ABNT, 2014), que exige a elaboração de um manual de utilização, inspeção e manutenção, contendo especificações para garantir a vida útil das estruturas. De forma complementar, a NBR 5674 (ABNT, 2012) trata exclusivamente do tema de requisitos para o sistema de gestão de manutenção de edificações. O presente trabalho tem como objetivo avaliar as metodologias de inspeção visual de edificações, particularmente a Metodologia GDE/UnB (Grau de Deterioração do Elemento) e a metodologia prescrita pela Norma de Inspeção Predial Nacional do IBAPE (Instituto Brasileiro de Avaliações e Perícias de Engenharia), visando incorporá-las em fluxos de processo para fins de gerenciamento de manutenções. Para o seu desenvolvimento, na primeira etapa, foram detalhadas, através de pesquisa bibliográfica, as características dessas metodologias e suas aplicabilidades, bem como o estudo das principais causas das manifestações patológicas que podem ocorrer nessas estruturas. Na segunda etapa, comparou-se os parâmetros de avaliação dessas metodologias. Com este trabalho, foi possível concluir que estas metodologias levam a resultados equivalentes, porém a Metodologia GDE/UnB se mostrou mais eficaz na escolha da intervenção primária.

Palavras-chave: inspeção predial, gerenciamento de manutenções, concreto armado.

\section{ABSTRACT}

The determination of the residual and service life of a building is closely linked to the planning and execution of maintenance processes. The importance of this maintenance is highlighted by the Brazilian Association of Technical Standards - ABNT, in its technical standard NBR 6118 (ABNT, 2014), which requires the elaboration of a user manual, inspection and maintenance, containing specifications to ensure the structures service life. Complementarily, NBR 5674 (ABNT, 2012) exclusively deals with the theme of requirements for the building maintenance management system. This paper aims to evaluate the methodologies of visual inspection of buildings, particularly the GDE Methodology (Degree of Element Deterioration) / UnB and the methodology prescribed by the IBAPE (Brazilian Institute of Engineering Assessment and Expertise) National Building Inspection Standard, to incorporate them into process flows for maintenance management purposes. For its development, in the first stage, the characteristics of these methodologies and their applicability were detailed and the main causes of the pathological manifestations that may occur in these structures were studied. In the second stage, the evaluation parameters of these methodologies were compared. With this work, it was concluded that these methodologies lead to similar results, but the GDE Methodology / UnB was more effective in choosing the primary intervention.

Keywords: building inspection, maintenance management, reinforced concrete. 


\section{INTRODUÇÃO}

A determinação da vida útil residual e de projeto de uma edificação está intimamente ligada ao planejamento e execução dos processos de manutenção da mesma. A importância dessa manutenção é destacada pela Associação Brasileira de Normas Técnicas - ABNT, em sua norma técnica NBR 6118 (ABNT, 2014), que exige a elaboração de um manual de utilização, inspeção e manutenção, contendo especificações para garantir a vida útil das estruturas. De forma complementar, a NBR 5674 (ABNT, 2012) trata exclusivamente do tema de requisitos para o sistema de gestão de manutenção de edificações.

De forma a acompanhar o estado técnico de conservação, uso e manutenção das edificações, a inspeção predial se torna uma ferramenta indispensável. Desde 2001, alguns municípios brasileiros tornaram obrigatória a inspeção predial regular das edificações (VERVLOET, 2018). Tem-se como exemplo, Salvador (BA), a Lei № 5.907 (SALVADOR, Lei 5.907, 2001); Fortaleza (FORTALEZA, Lei $\mathrm{n}^{\circ}$ 9.913, 2012); e outros Municípios que também criaram leis tornando obrigatória a inspeção predial regular (DOLACIO, 2013), devido à ocorrência de acidentes com causas relacionadas à falta de conservação dos edifícios. A Associação Brasileira de Normas Técnicas (ABNT), que é o órgão regulador nacional, não possui normativo publicado acerca das recomendações técnicas da atividade de inspeção predial. Entretanto, o Instituto Brasileiro de avaliações e Perícias de Engenharia (IBAPE) elaborou a Norma de Inspeção Predial Nacional, que objetiva:

'Esta norma fixa as diretrizes, conceitos, terminologia, convenções, notações, critérios e procedimentos relativos à inspeção predial, cuja realização é de responsabilidade e da exclusiva competência dos profissionais, engenheiros e arquitetos, legalmente habilitados pelos Conselhos Regionais de Engenharia e Agronomia - CREAs -, de acordo com a Lei Federal 5194 de 21/12/1966 e resoluções do CONFEA e Conselhos de Arquitetura e Urbanismo - CAUs - Lei $\mathrm{n}^{\circ} 12.378$ de 31/12/2010 e resoluções do CAU-BR' (IBAPE, 2012, p.3)

Outra metodologia utilizada para a inspeção de estruturas é a metodologia criada no Programa de Pós-Graduação em Estruturas e Construção Civil da Universidade de Brasília (PECC-UnB) com o intuito de realizar a avaliação quantitativa do grau de deterioração de estruturas de concreto, denominada metodologia de Grau de Deterioração do Elemento (GDE/UnB) (CASTRO, 1994).

Sendo assim, o presente trabalho tem como objetivo avaliar as metodologias de inspeção visual de edificações, particularmente, a Norma de Inspeção Predial Nacional do IBAPE (Instituto Brasileiro de Avaliações e Perícias de Engenharia) e a Metodologia GDE/UnB (Grau de Deterioração do Elemento), visando incorporá-las em fluxos de processo para fins de gerenciamento de manutenções.

\section{METODOLOGIA DE INSPEÇÃO EM EDIFICAÇÕES}

A seguir serão apresentadas e detalhadas as metodologias a serem comparadas neste trabalho, nomeadamente a Metodologia GDE/UnB e a Norma de Inspeção Predial Nacional do IBAPE.

\subsection{Metodologia GDE/UnB}

A metodologia Grau de Deterioração do Elemento (GDE/UnB) foi desenvolvida por Castro (1994) e revisada por Fonseca (2007), e consiste na proposta para a manutenção de estruturas de concreto armado de edificações usuais, de forma a quantificar o grau de deterioração da estrutura $\left(\mathrm{G}_{\mathrm{d}}\right)$, calculando o grau do dano (D), grau de deterioração do elemento $\left(\mathrm{G}_{\mathrm{de}}\right)$ e grau de deterioração da família de elementos $\left(\mathrm{G}_{\mathrm{df}}\right)$. De acordo com as consequências das patologias em relação à condição estética, a metodologia estabelece valores para o fator de ponderação $\left(\mathrm{F}_{\mathrm{p}}\right)$, que podem variar de 1 a 5. Além disso, ao realizar uma inspeção da estrutura, o fator de intensidade $\left(\mathrm{F}_{\mathrm{i}}\right)$ determina as possíveis lesões que o elemento pode apresentar e varia de 0 a 4 , conforme a Tabela 1 : 


\section{CBPAT 2020 \\ CONGRESSO BRASILEIRO DE PATOLOGIA DAS CONSTRUÇÕES

Tabela 1 - Classificação do Fator de Intensidade $\left(\mathrm{F}_{\mathrm{i}}\right)$.

\begin{tabular}{c|c}
\hline$F_{i}$ & Lesões \\
\hline 0 & Sem lesões \\
\hline 1 & Lesões leves \\
\hline 2 & Lesões toleráveis \\
\hline 3 & Lesões graves \\
\hline 4 & Estado Crítico \\
\hline \multicolumn{2}{|c}{ Fonte· CASTRO (1994) }
\end{tabular}

Essa metodologia sofreu modificações por Lopes (1998), quando observado que este critério poderia levar, algumas vezes, a resultados incoerentes. Dessa maneira, Lopes (1998) modificou a fórmula do grau de deterioração do elemento $\left(\mathrm{G}_{\mathrm{de}}\right)$ (Equação 02). Boldo (2002), utilizou o princípio de Lopes (1998) para o grau de deterioração da família $\left(\mathrm{G}_{\mathrm{df}}\right)$, em diferentes edificações, alterando-se sua denominação no Caderno de Inspeções para Inspeção para Estruturas de Concreto. Posteriormente, Fonseca (2007) utilizou a metodologia GDE/UnB para calcular o grau de deterioração de estruturas de concreto armado, além de alterar as formulações dos cálculos do Grau de deterioração da família $\left(\mathrm{G}_{\mathrm{df}}\right)$ (Equacão 03) e do Grau do Dano (D) (Equação 01) e apresentar uma mudança nos tipos mais usuais de danos (BOAS et al., 2018). Para a avaliação de estruturas em Concreto Armado, foram utilizadas as seguintes formulações, adaptadas por Fonseca (2007):

\subsubsection{Grau de Dano (D)}

$$
\begin{gathered}
D=0,8 F_{i} F_{p} \quad \text { para } \mathrm{F}_{\mathrm{i}} \leq 2 \\
D=\left(12 F_{i}-28\right) F_{p} \quad \text { para } \mathrm{F}_{\mathrm{i}}>2
\end{gathered}
$$

Sendo:

D: Grau do Dano

$\mathrm{F}_{\mathrm{i}}$ : Fator de Intensidade

$F_{p}$ : Fator de Ponderação

2.1.2 Grau de Deterioração de um elemento $\left(\mathrm{G}_{\mathrm{de}}\right)$

Em que:

$$
G_{d e}=D_{\max }\left[1+\frac{\sum_{i=1}^{m} D_{(i)}-D_{\text {máx }}}{\sum_{i=1}^{m} D_{(i)}}\right]
$$

$\mathrm{G}_{\mathrm{de}}=\mathrm{Grau}$ de deterioração de um elemento estrutural;

$\mathrm{D}_{\text {máx }}=$ Maior grau de dano no elemento;

m: Número de danos detectados no elemento; e

$\mathrm{D}_{(\mathrm{i})}$ : O grau de dano de ordem (i).

Com base no valor encontrado para o $\mathrm{G}_{\mathrm{de}}$, tem-se a classificação do nível de deterioração e as medidas a serem tomadas, conforme Tabela 2 . 
Tabela 2 - Classificação dos níveis de deterioração do elemento $\left(\mathrm{G}_{\mathrm{de}}\right)$.

\begin{tabular}{|c|c|c|}
\hline Nível de Deterioração & $\mathrm{G}_{\mathrm{de}}$ & Ações a serem tomadas \\
\hline Baixo & $0-15$ & Estado acertável. Manutenção preventiva. \\
\hline Médio & $15-50$ & $\begin{array}{c}\text { Definir prazo/natureza para nova inspeção. Em } \\
\text { médio prazo (máx. } 2 \text { anos) }\end{array}$ \\
\hline Alto & $50-80$ & $\begin{array}{l}\text { Definir prazo para inspeção especializada detalhada. } \\
\text { Em curto prazo (máx. } 1 \text { ano) }\end{array}$ \\
\hline Sofrível & $80-100$ & $\begin{array}{l}\text { Definir prazo para inspeção especializada detalhada. } \\
\text { Em curto prazo (máx. } 6 \text { meses). }\end{array}$ \\
\hline Crítico & $>100$ & Planejar intervenção imediata \\
\hline
\end{tabular}

Fonte: Adaptada de FONSECA (2007).

\subsubsection{Grau de Deterioração de uma família $\left(\mathrm{G}_{\mathrm{df}}\right)$}

Utiliza-se a Equação 03 apenas para elementos com nível de deterioração superior ou médio, ou seja, $\mathrm{G}_{\mathrm{de}} \geq 15$.

$$
G_{d f}=G_{\text {demáx }} \sqrt{1+\frac{\sum_{i=1}^{m} G_{d e(i)}-G_{\text {demáx }}}{\sum_{i=1}^{m} G_{d e(i)}}}
$$

Em que:

$\mathrm{G}_{\mathrm{df}}$ : Grau de deterioração de uma família de elementos;

$\mathrm{G}_{\text {demáx: }}$ Grau de deterioração máxima do elemento;

$\mathrm{G}_{\text {de(i): }}$ Grau de deterioração do elemento de ordem (i);

\subsubsection{Fator de Relevância Estrutural $\left(F_{r}\right)$}

O fator de relevância estrutural tem por objetivo considerar a importância relativa das diversas famílias que subdividem a estrutura, quanto ao comportamento e desempenho. Na Tabela 3 tem-se a classificação do $\mathrm{F}_{\mathrm{r}}$.

Tabela 3 - Classificação do Fator de Relevância Estrutural $\left(\mathrm{F}_{\mathrm{r}}\right)$.

\begin{tabular}{c|l}
\hline Fator de relevância Estrutural $\left(\mathrm{F}_{\mathrm{r}}\right)$ & \multicolumn{1}{c}{ Elementos analisados } \\
\hline 1,0 & Elementos de composição arquitetônica \\
\hline 2,0 & Reservatório superior. \\
\hline 3,0 & $\begin{array}{l}\text { Escadas/rampas, reservatório inferior, cortinas, lajes } \\
\text { secundárias, juntas de dilatação. }\end{array}$ \\
\hline 4,0 & Lajes, fundações, vigas secundárias. \\
\hline 5,0 & Vigas e pilares principais. \\
\hline
\end{tabular}

Fonte: FONSECA (2007).

\subsubsection{Grau de Deterioração da Estrutura $\left(\mathrm{G}_{\mathrm{d}}\right)$}

A partir das informações obtidas anteriormente, é possível calcular o grau de deterioração da estrutura (Equação 04) e classificá-lo de acordo com a Tabela 4. 


$$
G_{d}=\frac{\sum_{i=l}^{K} F_{r(i)} G_{d f(i)}}{\sum F_{r(i)}}
$$

Tabela 4 - Classificação dos níveis de deterioração da estrutura $\left(\mathrm{G}_{\mathrm{d}}\right)$.

\begin{tabular}{c|c|c}
\hline $\begin{array}{c}\text { Nível de deterioração } \\
\text { Baixo }\end{array}$ & $\begin{array}{c}\mathrm{G}_{\mathrm{d}} \\
\text { Médio }\end{array}$ & $\begin{array}{c}\text { Ações a serem tomadas } \\
\text { Estado aceitável. Manutenção preventiva. }\end{array}$ \\
\hline Alto & $50-80$ & $\begin{array}{c}\text { Definir prazo/natureza para nova inspeção. Em médio prazo (máx. 2 } \\
\text { anos) }\end{array}$ \\
\hline Sofrível & $80-100$ & $\begin{array}{c}\text { Definir prazo para inspeção especializada detalhada. Em curto prazo } \\
\text { (máx. 6 meses). }\end{array}$ \\
\hline Crítico & $>100$ & Planejar intervenção imediata \\
\hline
\end{tabular}

Fonte: Adapatada de FONSECA (2007).

\subsection{Norma de Inspeção Predial Nacional do IBAPE}

Nos EUA e no Canadá, a Inspeção Predial é um pré-requisito em qualquer transação imobiliária, sendo obrigatória a entrega do laudo de inspeção para a assinatura dos contratos. No Brasil, as transações imobiliárias são diferentes, uma vez que grande parte das negociações são concretizadas considerando as informações fornecidas pelo atual proprietário do imóvel ou pelo intermediador da venda, ignorando as informações técnicas que deveriam ser elaboradas por um profissional especializado. Com o laudo de inspeção predial em mãos, o comprador e/ou usuário estaria com as informações técnicas fundamentadas, capazes de orientá-lo na negociação do valor ou até mesmo direcioná-lo em sua decisão de compra. Além disso, o laudo de inspeção predial é uma importante ferramenta no auxílio para identificação de anomalias e falhas. (NEVES e BRANCO, 2009.)

De acordo com a Norma de Inspeção Predial do IBAPE (2012, p.5), a inspeção predial é a "análise isolada ou combinada das condições técnicas, de uso e de manutenção da edificação". O método de avaliação técnica descrito nessa norma consiste nos seguintes procedimentos:
a) Determinação do nível de inspeção;
b) Verificação e análise da documentação;
c) Obtenção de informações dos usuários, responsáveis, proprietários e gestores das edificações;
d) Vistoria dos tópicos constantes na listagem de verificação;
e) Classificação das anomalias e falhas constatadas nos itens vistoriados, e das não conformidades com a documentação examinada;
f) Classificação e análise das anomalias e falhas quanto ao grau de risco;
g) Definição de prioridades;
h) Recomendações técnicas;
i) Avaliação da manutenção e uso;
j) Recomendações gerais e de sustentabilidade;
k) Tópicos essenciais do laudo;
1) Responsabilidades.

\subsubsection{Determinação do nível da inspeção}

Classifica-se a Inspeção Predial conforme a sua complexidade e elaboração de laudo, conforme as características da edificação, manutenção e operação existentes e a necessidade de equipe multidisciplinar para realização dos trabalhos. Os níveis de inspeção predial podem ser divididos em nível 1, nível 2 e nível 3 (Tabela 5). 
Tabela 5 - Nível da Inspeção.

\begin{tabular}{c|c}
\hline Nível de Inspeção & Ações \\
\hline Nível 1 & $\begin{array}{c}\text { Edificações mais simples, normalmente sem a } \\
\text { necessidade de equipe multidisciplinar. }\end{array}$ \\
\hline Nível 2 & $\begin{array}{c}\text { Edifícios multifamiliares, comerciais sem } \\
\text { sistemas construtivos mais complexos. Pode } \\
\text { envolver equipe multidisciplinar }\end{array}$ \\
\hline Nível 3 & $\begin{array}{c}\text { Edificações complexas. Sempre envolve } \\
\text { equipe multidisciplinar. }\end{array}$ \\
\hline
\end{tabular}

Fonte: Adaptado de IBAPE (2012).

\subsubsection{Verificação e análise da documentação}

Quando disponível, é recomendável analisar os documentos administrativos, técnicos, de manutenção e de operação da edificação (Tabela 6).

Tabela 6 - Referencias usuais de Documentação.

\begin{tabular}{c|l}
\hline Documentos & \multicolumn{1}{c}{ Referências usuais } \\
\hline \multirow{5}{*}{ Administrativos } & $\begin{array}{l}\text { Instituição, Especificação e Convenção de Condomínio; Regimento } \\
\text { Interno do Condomínio; Alvará de Construção; Auto de Conclusão; }\end{array}$ \\
& $\begin{array}{l}\text { IPTU; Programa de Prevenção de Riscos Ambientais (PPRA); Alvará } \\
\text { do Corpo de Bombeiros; Ata de instalação do condomínio; Alvará de } \\
\text { funcionamento; Certificado de Manutenção do Sistema de Segurança; } \\
\text { Certificado de treinamento de brigada de incêndio; Licença de } \\
\text { funcionamento da prefeitura; Licença de funcionamento do órgão } \\
\text { ambiental estadual; Cadastro no sistema de limpeza urbana; } \\
\text { Comprovante da destinação de resíduos sólidos, etc. Relatório de danos } \\
\text { ambientais, quando pertinente; Licença da vigilância sanitária, quando } \\
\text { pertinente; Contas de consumo de energia elétrica, água e gás; PCMSO - } \\
\text { Programa de Controle Médico de Saúde Ocupacional; Alvará de } \\
\text { funcionamento; e Certificado de Acessibilidade }\end{array}$ \\
\hline \multirow{5}{*}{$\begin{array}{l}\text { Memonicosial descritivo dos sistemas construtivos; Projeto executivo; } \\
\text { Operação }\end{array}$} & $\begin{array}{l}\text { Mrojeto de estruturas; Projetos de Instalações Prediais: Projeto de } \\
\text { Revestimentos em geral; Projeto de paisagismo. }\end{array}$ \\
\hline $\begin{array}{l}\text { Manual de Uso, Operação e Manutenção; Plano de Manutenção e } \\
\text { Operação e Controle Selos dos Extintores; Relatório de Inspeção Anual } \\
\text { de Elevadores; Atestado do Sistema de Proteção a Descarga } \\
\text { Atmosférica; Certificado de limpeza e desinfeção; Relatório das } \\
\text { análises físico-químicas de potabilidade de água dos reservatórios e da } \\
\text { rede; Certificado de ensaios de pressurização em mangueiras. }\end{array}$ \\
\hline
\end{tabular}

Fonte: Adaptado de IBAPE (2012).

2.2.3 Obtenção de informações dos usuários, responsáveis, proprietários e gestores das edificações

Para a elaboração do laudo de vistoria é importante, também, realizar entrevista com gestor ou síndico para obtenção de informações sobre o uso do local, histórico de reformas e manutenções, dentre outras intervenções ocorridas.

\subsubsection{Vistoria dos tópicos constantes na listagem de verificação}

A listagem de verificação se refere ao conjunto de tópicos a serem vistoriados, considerado o número mínimo de itens abordados em uma inspeção, de acordo com a sua complexidade. Para que a vistoria na inspeção predial seja sistêmica e que abranja, os seguintes sistemas construtivos e seus elementos: estrutura, impermeabilização, instalações hidráulicas e elétricas, revestimentos externos em geral, esquadrias, revestimentos internos, elevadores, climatização, exaustão mecânica, ventilação, coberturas, telhados, combate a incêndio e SPDA. 


\subsubsection{Classificação das anomalias e falhas}

As anomalias e falhas são não conformidades que acarretam na perda precoce de desempenho real ou futuro dos elementos de sistemas construtivos, e redução de sua vida útil. Podem comprometer a segurança, funcionalidade, operacionalidade, saúde de usuários, conforto térmico, acessibilidade, durabilidade, vida útil, e outros critérios de desempenho conforme estabelece a NBR 15575 (ABNT, 2013). As anomalias e falhas podem ser classificadas conforme a Tabela 7 .

Tabela 7 - Classificação de não conformidade.

\begin{tabular}{c|l}
\hline Não Conformidade & \multicolumn{1}{c}{ Classificação } \\
\hline \multirow{2}{*}{ Anomalias } & $\begin{array}{l}\text {-Endógena: Própria edificação } \\
\text {-Exógena: Fatores externos; } \\
\text {-Natural: Fenômenos da natureza; } \\
\text { Falhas }\end{array}$ \\
\hline \multirow{2}{*}{-Funcional: Término da vida útil } \\
\hline -Planejamento: Especificações inadequadas; \\
-Execução: Execução inadequada \\
-Operacionais: Procedimentos inadequados; \\
-Gerenciais: Falta de controle de qualidade dos serviços.
\end{tabular}

Fonte: Adaptado de IBAPE (2012).

Para análise do grau de risco devem ser considerados: fatores de conservação, as manutenções previstas, agentes de deterioração precoce, depreciação, riscos à saúde, segurança, funcionamento e comprometimento de vida útil. Os graus de risco são classificados em estado crítico, regular e mínimo (Tabela 8).

Tabela 8 - Classificação do grau de risco.

\begin{tabular}{c|l}
\hline Grau de Risco & \multicolumn{1}{c}{ Classificação } \\
\hline Crítico & Risco de provocar danos contra a saúde e segurança das pessoas; \\
\hline Médio & Risco de provocar perda parcial de desempenho e funcionalidade \\
\hline Mínimo & Risco de causar pequenos prejuízos a estética ou atividade planejada \\
\hline
\end{tabular}

Fonte: Adaptado de IBAPE (2012).

\subsubsection{Definição de Prioridades}

De acordo com a ordem do problema constatado, deve-se elaborar uma lista de prioridades técnicas, onde essa lista é ordenada do mais crítico ao menos crítico, sendo estabelecidas através de metodologias técnicas específicas, sendo uma delas a elas a matriz GUT.

O método GUT é utilizado para o gerenciamento de risco que leva em consideração a Gravidade (G), a Urgência (U) e a Tendência (T) dos problemas a serem inspecionados. De acordo com DIAS et al., 2018, para realizar essa a avaliação, o sistema estebelece os pesos que são destinados a classificação de cada item inspecionado, com o intuito de definir graus de criticidade em relação aos problemas encontrados (Tabela 9). 
Tabela 9- Classificação GUT.

\begin{tabular}{|c|c|c|}
\hline Grau & Gravidade & Peso \\
\hline Total & Perda de vidas humanas, do meio ambiente ou do próprio edifício & 10 \\
\hline Alta & Ferimentos em pessoas, danos ao meio ambiente ou ao edifício & 6 \\
\hline Média & Desconfortos, deterioração do meio ambiente ou do edifício & 3 \\
\hline Baixa & Pequenos incômodos ou pequenos prejuízos financeiros & 1 \\
\hline Nenhuma & Nenhuma & Peso \\
\hline Grau & Urgência & 10 \\
\hline Total & Evento em ocorrência & 6 \\
\hline Alta & Evento prestes a ocorrer & 3 \\
\hline Média & Evento prognosticado para breve & 1 \\
\hline Baixa & Evento prognosticado para adiante & Peso \\
\hline Nenhuma & Evento imprevisto & 10 \\
\hline Grau & Tendência & 8 \\
\hline Total & Evolução imediata & 6 \\
\hline Alta & Evolução em curto prazo & 3 \\
\hline Média & Evolução em médio prazo & \\
\hline Baixa & Evolução em logo prazo & \\
\hline
\end{tabular}

Fonte: DIAS et al., 2018.

Ao final da atribuição dos pesos para os problemas é calculado o produto $(\mathrm{G}) \mathrm{x}(\mathrm{U}) \mathrm{x}(\mathrm{T})$. O resultado definirá qual o grau de prioridade do problema. Para organizar os dados, é importante a elaboração de "planilhas de prioridades" a qual indicará a lista de prioridades para intervenções.

\subsubsection{Recomendações Técnicas}

Com base no que foi constatado elaboram-se recomendações ou orientações técnicas para a solução dos problemas, podendo estar relacionadas à adequação do plano de manutenção ou aos reparos e reformas para solução de anomalias. Deve-se indicar manuais, ilustrações e normas pertinentes para facilitar o entendimento do contratante.

\subsubsection{Avaliação da Manutenção e Uso}

Para realizar a avaliação da manutenção é preciso analisar o plano de manutenção para a edificação e as respectivas condições de execução. Em caso de ausência do plano de manutenção na edificação, o profissional responsável pela inspeção, precisará verificar as atividades realizadas e devidamente registradas, comparando-as com o conjunto de recomendações mínimas de fabricantes e fornecedores dos equipamentos e sistemas.

Outro ponto importante a ser avaliado diz respeito ao uso da edificação. Tal avaliação, denominada Avaliação do Uso da Edificação pode ser classificada como: regular ou irregular, devendo, para isso, observar as condições originais da edificação e os seus sistemas construtivos.

Uso Regular- Quando a edificação inspecionada encontra-se ocupada e utilizada de acordo com o uso previsto no projeto.

Uso Irregular - Quando a edificação inspecionada encontra-se ocupada e utilizada de forma irregular, com o uso divergente do previsto no projeto.

\subsubsection{Recomendações gerais e de sustentabilidade}

A definição de sustentabilidade refere-se há aspectos como o uso racional de recursos naturais, a preservação do conforto e segurança de usuários, assim como a preservação do meio ambiente (permeabilidade de solos, descartes irregulares para redes públicas, etc). Sendo assim, deve-se indicar medidas de correção e melhoria da edificação que possam favorecer a sustentabilidade. 


\subsubsection{Tópicos Essenciais no Laudo}

Realizada a inspeção predial, é necessário a elaboração do laudo técnico. Para sua construção, há itens importantes que devem constar na em sua estrutura (Tabela 10).

Tabela 10 - Itens que devem constar no Laudo da Inspeção Predial.

\begin{tabular}{|c|c|}
\hline 1 & Identificação do Solicitante \\
\hline 2 & Classificação do objeto \\
\hline 3 & Localização \\
\hline 4 & Data da Diligência \\
\hline 5 & Descrição Técnica do Objeto \\
\hline 6 & Tipologia e padrão construtivo \\
\hline 7 & Utilização e Ocupação \\
\hline 8 & Idade da Edificação \\
\hline 9 & Nível Utilizado \\
\hline 10 & Documentação solicitada, entregue e \\
& analisada \\
\hline 11 & Descrição do Critério e Método da Inspeção \\
& predial \\
\hline
\end{tabular}

\begin{tabular}{|c|c|}
\hline 13 & $\begin{array}{c}\text { Lista de verificação dos elementos } \\
\text { construtivos e equipamentos vistoriados, } \\
\text { descrição e localização das respectivas } \\
\text { anomalias e falhas. }\end{array}$ \\
\hline 14 & $\begin{array}{c}\text { Classificação das anomalias e falhas quanto } \\
\text { ao grau de risco }\end{array}$ \\
\hline 15 & Indicação de prioridade \\
\hline 16 & $\begin{array}{l}\text { Avaliação da manutenção e condições de uso } \\
\text { da Edificação e dos sistemas construtivos }\end{array}$ \\
\hline 17 & Recomendações Técnicas \\
\hline 18 & Recomendações gerais e de sustentabilidade \\
\hline 19 & Relatório fotográfico \\
\hline 20 & $\begin{array}{l}\text { Recomendação do prazo para nova inspeção } \\
\text { predial }\end{array}$ \\
\hline 21 & Data do Laudo \\
\hline 22 & Assinatura do profissional responsável \\
\hline 23 & $\begin{array}{c}\text { Anotação da Responsabilidade Técnica } \\
\text { (ART) ou Registro de Responsabilidade } \\
\text { Técnica (RRT) } \\
\end{array}$ \\
\hline
\end{tabular}

Fonte: IBAPE (2012).

\section{METODOLOGIA}

Como a norma de Inspeção Predial do IBAPE e a Medologia GDE/UnB possuem a finalidade de nortear os trabalhos de inspeção predial em edificações, foi possível obter a comparação das premissas básicas de ambas as metodologias. Essa comparação permitiu e a análise das situações sobre a melhor aplicabilidade de cada uma delas. Outro fator importante foi o fato de que as metodologias supracitadas são de aplicação visual, não sendo necessário nenhum uso de equipamento especial ou análises destrutivas.

Para o desenvolvimento do trabalho, na primeira etapa, foram detalhadas, através de pesquisa bibliográfica, as características dessas metodologias e suas aplicabilidades, bem como o estudo das principais causas das manifestações patológicas que podem ocorrer nessas estruturas. Na segunda etapa, comparou-se os parâmetros de avaliação dessas metodologias.

\section{RESULTADOS E DISCUSSÕES}

As duas metodologias apresentadas possuem semelhanças e diferenças na avaliação de uma edificação. É importante destacar que a metodologia GDE/UnB avalia o grau de deterioração da estrutura, já a Norma de Inspeção Predial Nacional do IBAPE avalia os diferentes elementos da edificação. A Tabela 11 apresenta uma comparação entre os dois métodos de inspeção. 
Tabela 91 - Comparação geral entre metodologias de inspeção predial.

\begin{tabular}{|c|c|c|}
\hline Dados & Norma do IBAPE & Metodologia GDE/UnB \\
\hline Ano da última revisão & 2012 & Castro (1994) \\
\hline Elaborador & IBAPE Nacional & Inspeção Visual \\
\hline Estratégia de Inspeção & $\begin{array}{c}\text { Inspeção Visual, testes e ensaios } \\
\text { locais e/ou laboratoriais específicos. }\end{array}$ & Estrutural \\
\hline Parâmetros & $\begin{array}{c}\text { Estrutura, impermeabilização, } \\
\text { instalações } \\
\text { hidráulicas e elétricas, revestimentos } \\
\text { externos em geral, esquadrias, } \\
\text { revestimentos internos, } \\
\text { elevadores, climatização, exaustão } \\
\text { mecânica, ventilação, coberturas, } \\
\text { telhados, combate a } \\
\text { incêndio e SPDA }\end{array}$ \\
\hline Escala de Classificação & $\begin{array}{c}\text { 1x1x1 a 10x10x10 } \\
\text { (GUT) }\end{array}$ & \\
\hline
\end{tabular}

Fonte: autores.

A partir da análise das características de cada metodologia, inicialmente, pode-se observar algumas limitações da Metodologia GDE/UnB perante a norma de inspeção predial do IBAPE quanto a estratégia de Inspeção Predial e quanto aos parâmetros da análise da vistoria. A norma do IBAPE tem o intuito de verificar todos os elementos da edificação; em contrapartida a Metodologia GDE/UnB avalia apenas a condição estrutural da edificação (vigas, lajes, vigas secundárias, pilares, elementos de composição arquitetônica, escada/rampas).

Com relação a classificação, o grau de Prioridade estabelecido pela Norma do IBAPE se assemelha a classificação dada ao Grau de Deterioração da Estrutura. O primeiro gera uma lista de prioridades visando determinar uma ordem de prioridades das atividades necessárias para a correção das anomalias identificadas, já o segundo define o prazo para se realizar a intervenção na família analizada.

Pode-se observar que ao indicar os prazos para a realização de uma intervenção, a metodologia GDE/UnB se mostra mais eficar na escolha de uma intervenção primária. Sendo assim, no quesito de avaliação estrutural, ambas as metodologias podem se complementar. De forma que GDE/UnB poderia ser utilizada como uma metodologia de inspeção estrutural dos elementos para a Norma de Inspeção Predial do IBAPE, assim como, a Matriz GUT é utilizada atualmente.

\section{CONCLUSÕES}

Diante do exposto, pode-se observar que ambas as metodologias tendem a apresentar resultados semelhantes. Entretanto, a Metodologia GDE/UnB se mostrou mais eficaz em uma escolha de intervenção estrutural primária, uma vez que indica prazos para a realização de uma intervenção em famílias específicas do edifício.

Outro fator importante a se considerar, é que a Norma de Inspeção Predial do IBAPE permite uma inspeção completa, englobando diversos sistemas construtivos. Já a Metodologia GDE/UnB permite a classificação somente de elementos de estruturas em concreto armado.

Sendo assim, os métodos citados podem ser utilizados para se complementarem em termos de análise de elementos estruturais, uma vez que a Metodologia GDE/UnB poderia ser utilizada na classificação das prioridades de intervenção. Isto está diretamente relacionado ao fluxo de processos para fins de gerenciamento de manutenções, o que auxiliaria no estabelecimento de prazos para a realização de novas intervenções, de forma que a inspeção predial ficasse mais eficiente. 


\section{AGRADECIMENTOS}

Agradecemos ao Centro Federal de Educação Tecnológica de Minas Gerais - CEFET-MG pelo apoio direto e indireto a este trabalho, em especial ao LAR - Laboratório de Avaliação e Reabilitação de Ambiente Construído do CEFET-MG Campus Curvelo.

\section{REFERÊNCIAS}

ASSOCIAÇÃO BRASILEIRA DE NORMAS TÉCNICAS (ABNT). NBR 6118: Projeto de estruturas de concreto Procedimento. Rio de Janeiro: ABNT, 2014.

ASSOCIAÇÃO BRASILEIRA DE NORMAS TÉCNICAS (ABNT). NBR 15575: Edificações habitacionais Desempenho. Rio de Janeiro: ABNT, 2013.

ASSOCIAÇÃO BRASILEIRA DE NORMAS TÉCNICAS (ABNT). NBR 5674: Manutenção de edificações Requisitos para o sistema de gestão de manutenção. Rio de Janeiro: ABNT, 2012.

BOAS, E. et al . Aplicação de Metodologia GDE/UnB em uma edificação habitacional: Estudo de caso em Águas Lindas de Goiás- GO. CONGRESSO BRASILEIRO DO CONCRETO, Goías, 2018. Disponível em $<$ http://ibracon.org.br/eventos/adminx/artigos/60CBC2024-ver4-autor-

APLICA\%C3\%87\%C3\%83O\%20DE\%20METODOLOGIA\%20GDE\%20UnB\%20EM\%20UMA\%20EDIFICA\%C3\% 87\%C3\%83O $\% 20$ HABITACIONAL $\% 20 \% 20$ ESTUDO $\% 20$ DE $\% 20$ CASO $\% 20$ EM $\% 20 \%$ C3\%81GUAS\%20LINDAS \%20DE\%20GOI\%C3\%81S-\%20GO.pdf> . Acesso em: 07 set. 2019.

BOLDO, P., Análise Quantitativa de Estruturas de Concreto Armado de Edificações no Âmbito do Exército Brasileiro. Dissertação (Mestrado em Estruturas), Departamento de Engenharia Civil e Ambiental, Universidade de Brasília, Brasília, DF, 2002.

CASTRO, E.K., Desenvolvimento de Metodologia para Manutenção de Estruturas de Concreto Armado. Dissertação (Mestrado em Estruturas), Departamento de Engenharia Civil, Universidade de Brasília, Brasília, DF, 1994.

DIAS, S. et al. Importância Das Inspeções Prediais Na Redução De Patologias: Estudo De Caso Em Teresina-PI. CONFERÊNCIA SOBRE PATOLOGIA E RECUPERAÇÃO DE EDIFICIOS, Rio de Janeiro, 2018. Disponível em < http://www.nppg.org.br/patorreb/files/artigos/80652.pdf> . Acesso em: 06 jan. 2020.

DOLACIO, A. C., A obrigatoriedade da inspeção predial. In: XVII Congresso Brasileiro de Engenharia de Avaliação e Perícias. Florianópolis, SC, 2013. Disponível em <http://ibape-nacional.com.br/site/wpcontent/themes/Nicol/documentos-xvicobreap/A\%20 OBRIGATORIEDADE\%

20DA\%20INSPE\%C7\%C3O\%20PREDIAL\%20Antonio\%20Carlos\%20Dalocio.pdf>. Acesso em: 10 out. 2019.

FONSECA, R.P., A estrutura do Instituto Central de Ciências: Aspectos históricos, científicos e tecnológicos de projeto, execução, intervenções e propostas de manutenção. Dissertação (Mestrado em Estruturas e Construção Civil), Departamento de Engenharia Civil e Ambiental, Universidade de Brasília. Brasília, DF, 2007.

FORTALEZA. Lei No 9.913 de 16 de Julho de 2012. Dispõe sobre obrigatoriedade de vistoria técnica, manutenção preventiva e periódica das edificações e equipamentos públicos ou privados no âmbito do Município de Fortaleza, e dá outras providências. Fortaleza, CE, 2012. Disponível em < https://leismunicipais.com.br/a/ce/f/fortaleza/decreto/2015/1361/13616/decreto-n-13616-2015-regulame nta-lei-n-9913-de-16-de-julho-de-2012-que-dispoe-sobre-as-regras-gerais-e-especificas-a-serem-obedecidas-namanutencao-e-conservacao-das-edificacoes-no-municipio-de-fortaleza-e-da-outras-providencias>. Acesso em : 10 out. 2019.

Instituto Brasileiro de Avaliações e Perícias de Engenharia (IBAPE). Norma de Inspeção Predial, 2012. Disponível < http://ibape-nacional.com.br/biblioteca/wp-content/uploads/2012/12/Norma-de-Inspe\%C3\%A7\%C3\%A3o-PredialIBAPE-Nacional.pdf > Acesso em: 23 ago. 2019. 
LOPES, B.A.R., Sistema de manutenção estrutural para grandes estoques de edificações: Estudo para a inclusão do componente Estrutura de Concreto. Dissertação (Mestrado em Estruturas), Departamento de Engenharia Civil, Universidade de Brasília, Brasília, DF, 1998.

NEVES, D. R. R.; BRANCO, L. A. M. N., Estratégia de Inspeção Predial. In: Construindo, v.1, n.2, p.12-19. Belo Horizonte, MG, 2009.

SALVADOR. Lei No 5.907 de 27 de Setembro de 2001. Legislação do Município de Salvador que determina "obrigatória" realização de inspeção predial por profissional habilitado no CREA. Salvador, BA, 2001. Disponível em < https://leismunicipais.com.br/a/ba/s/salvador/decreto/2001/1325/13251/decreto-n-13251-2001-dispoe-sobre-aregulamentacao-da-lei-n-5907-de-23-de-janeiro-de-2001-e-da-outras-providencias>. Acesso em: 10 out. 2019.

VERVLOET, S. Análise de indicadores para execução de inspeção predial regular obrigatória e diretrizes para o corpo técnico. Dissertação (Mestrado em Engenharia Civil), Programa de Pós-Graduação em Engenharia Civil Universidade Federal do Espírito Santo, Vitória, 2018. 